\title{
Spatio-temporal patterns of the effects of precipitation variability and land use/cover changes on long-term changes in sediment yield in the Loess Plateau, China
}

\author{
Guangyao Gao ${ }^{1,2}$, Jianjun Zhang ${ }^{1}$, Yu Liu ${ }^{3}$, Zheng Ning ${ }^{1}$, Bojie Fu ${ }^{1,2}$, and Murugesu Sivapalan ${ }^{4,5}$ \\ ${ }^{1}$ State Key Laboratory of Urban and Regional Ecology, Research Center for Eco-Environmental Sciences, \\ Chinese Academy of Sciences, Beijing 100085, China \\ ${ }^{2}$ Joint Center for Global Change Studies, Beijing 100875, China \\ ${ }^{3}$ Key Laboratory of Ecosystem Network Observation and Modeling, Institute of Geographical Sciences and Natural \\ Resources Research, Chinese Academy of Sciences, Beijing 100101, China \\ ${ }^{4}$ Department of Geography and Geographic Information Science, University of Illinois at Urbana-Champaign, \\ Champaign, Illinois, USA \\ ${ }^{5}$ Department of Civil and Environmental Engineering, University of Illinois at Urbana-Champaign, \\ Urbana, Illinois, USA
}

Correspondence to: Guangyao Gao (gygao@rcees.ac.cn)

Received: 9 December 2016 - Discussion started: 2 January 2017

Revised: 5 August 2017 - Accepted: 8 August 2017 - Published: 7 September 2017

\begin{abstract}
Within China's Loess Plateau there have been concerted revegetation efforts and engineering measures since the 1950s aimed at reducing soil erosion and land degradation. As a result, annual streamflow, sediment yield, and sediment concentration have all decreased considerably. Humaninduced land use/cover change (LUCC) was the dominant factor, contributing over $70 \%$ of the sediment load reduction, whereas the contribution of precipitation was less than $30 \%$. In this study, we use 50-year time series data (1961-2011), showing decreasing trends in the annual sediment loads of 15 catchments, to generate spatio-temporal patterns in the effects of LUCC and precipitation variability on sediment yield. The space-time variability of sediment yield was expressed notionally as a product of two factors representing (i) the effect of precipitation and (ii) the fraction of treated land surface area. Under minimal LUCC, the square root of annual sediment yield varied linearly with precipitation, with the precipitation-sediment load relationship showing coherent spatial patterns amongst the catchments. As the LUCC increased and took effect, the changes in sediment yield pattern depended more on engineering measures and vegetation restoration campaign, and the within-year rainfall patterns (especially storm events) also played an important role. The
\end{abstract}

effect of LUCC is expressed in terms of a sediment coefficient, i.e., the ratio of annual sediment yield to annual precipitation. Sediment coefficients showed a steady decrease over the study period, following a linear decreasing function of the fraction of treated land surface area. In this way, the study has brought out the separate roles of precipitation variability and LUCC in controlling spatio-temporal patterns of sediment yield at catchment scale.

\section{Introduction}

Streamflow and sediment transport are important controls on biogeochemical processes that govern ecosystem health in river basins (Syvitski, 2003). Changes in soil erosion on landscapes and the resulting changes in sediment transport rates in rivers have great environmental and societal consequences, particularly since they can be brought about by climatic changes and human-induced land use/cover changes (LUCC) (Syvitski, 2003; Beechie et al., 2010). Understanding the dominant mechanisms behind such changes at different timescales and space scales is crucial to the development 
of strategies for sustainable land and water management in river basins (Wang et al., 2016).

In recent decades, streamflows and sediment yields in large rivers throughout the world have undergone substantial changes (Milly et al., 2005; Nilsson et al., 2005; Milliman et al., 2008; Cohen et al., 2014). Notable decreases in sediment yields have been observed in approximately $50 \%$ of the world's rivers (Walling and Fang, 2003; Syvitski et al., 2005). Many studies have investigated the dynamics of streamflows and sediment yields at different spatial and temporal scales (Mutema et al., 2015; Song et al., 2016; Gao et al., 2016). In addition to climate variability, LUCC, soil and water conservation measures (SWCMs) and construction of reservoirs and dams have substantially contributed to the sediment load reductions (Walling, 2006; Milliman et al., 2008; Wang et al., 2011). While previous studies have certainly provided valuable insights into the streamflow and sediment load changes, the distinctive roles of LUCC and precipitation variability in changing sediment loads still need further investigation in large domains and across gradients of climate and land surface conditions (Walling, 2006; Mutema et al., 2015). A particularly useful approach to the development of generalizable understanding of the effects of precipitation variability and LUCC is a comparative analysis approach focused on extracting spatio-temporal patterns of sediment yields based on observations in multiple locations within the same region, or even across different regions. This is especially valuable and crucial in areas with severe soil erosion and fragile ecosystems, e.g., the Loess Plateau (LP) in China, which is the motivation for the work presented in this paper.

The LP lies in the middle reaches of the Yellow River (YR) basin, and contributes nearly $90 \%$ of the YR sediment (Wang et al., 2016). The historically severe soil erosion in the LP is due to sparse vegetation, intensive rainstorms, erodible loessial soil, steep topography, and a long agricultural history (Rustomji et al., 2008). To control such severe soil erosion, several SWCMs, including terrace and check-dam construction, afforestation and pasture reestablishment, have been implemented since the 1950s (Yao et al., 2011; Zhao et al., 2017). A large ecological restoration campaign, the Grainfor-Green (GFG) project converting farmland on slopes that exceed $25^{\circ}$ to forest and pasture lands, was launched in 1999 (Chen et al., 2015). Furthermore, the climate in the LP region has been showing both warming and drying trends (i.e., increased potential evapotranspiration and reduced precipitation) since the 1950s (Zhang et al., 2016).

These substantial LUCC have notably altered the hydrological regimes of the LP in combination with the climate change. Consequently, the sediment yields within the LP have showed a predictable declining trend over the past 60 years (Zhao et al., 2017), resulting in approximately a $90 \%$ decrease in sediment yield in the YR (Miao et al., 2010, 2011; Wang et al., 2016). Many other studies have detected the influences of LUCC and precipitation variability on sediment load changes within the LP. Rustomji et al. (2008) esti- mated that the contribution of catchment management practices to the decrease in annual sediment yield ranged between 64 and $89 \%$ for 11 catchments in the LP during the 1950s to 2000. Zhao et al. (2017) examined the spatio-temporal variation of sediment yield from 1957 to 2012 across the LP, and indicated that the adoption of large-scale SWCMs led to significant reduction of sediment yield between Toudaoguai and Tongguan stations, and large reservoir operation played a critical role in sediment yield reduction between Tongguan and Huayuankou stations. Zhang et al. (2016) pointed out that the combined effects of climate aridity, engineering projects, and vegetation cover change-induced significant reductions of sediment yield between 1950 and 2008. Wang et al. (2016) found that engineering measures for soil and water conservation were the main factors for the sediment load decrease between the 1970s and 1990s, but large-scale vegetation restoration campaigns also played an important role in reducing soil erosion since the 1990s.

On the basis of the outcomes of these studies, it is now generally accepted that the largest reductions of sediment yield within the LP resulted from LUCC. However, this is general knowledge covering the whole region, and given the significant variability of climate and catchment characteristics across the LP (Sun et al., 2015a, b), it is important to go further and explore how these might affect spatio-temporal patterns of sediment yield. Exploration of these patterns is important for sustainable ecosystem restoration and water resources planning and management within the LP. They will also serve as the basis for future research aimed at the development of a more generalizable understanding of landscape and climate controls on sediment yields at the catchment scale.

Most of the sediment yield of the LP was produced in the Coarse Sandy Hilly Catchments (CSHC) region (Fig. 1) located in the central region of the LP. The CSHC supplied over $70 \%$ of the total sediment load in the YR, especially coarse sand (Rustomji et al., 2008). This region was the focus of our efforts to investigate the variation of sediment load from 15 catchments within the region within the LP. The specific objectives of this study were, therefore, to (1) attribute the temporal changes in sediment yield to changes in both precipitation variability and LUCC over the entire study period (1961-2011) within the CSHC region, (2) extract spatiotemporal trends in sediment yields on the basis of annual sediment yield data, and (3) separate the contributions of precipitation variability and the fractional area of LUCC to the observed spatio-temporal patterns of sediment yields, and pave the way for more detailed process-based studies in the future. 


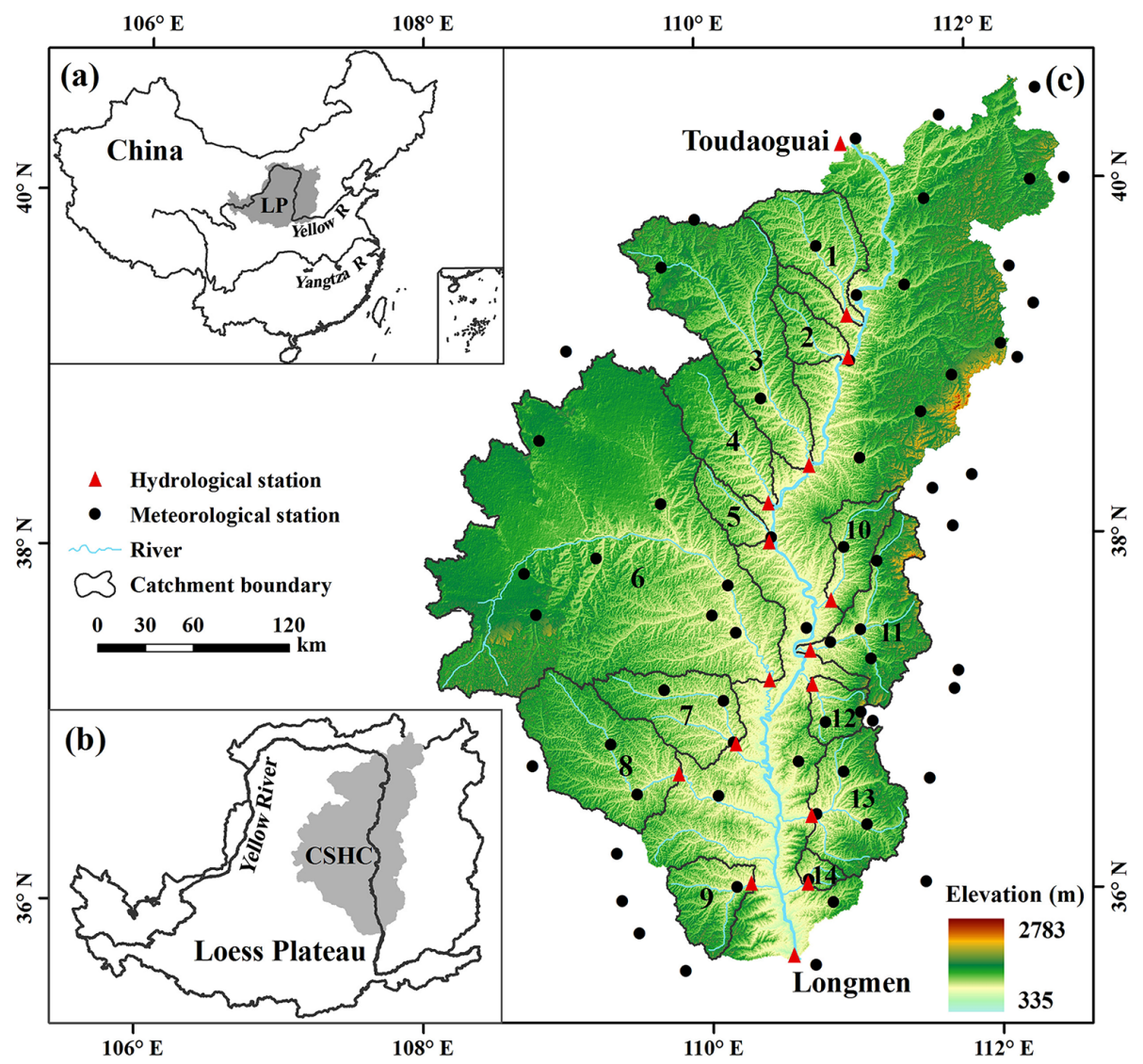

Figure 1. Location of the studied catchments in the Coarse Sandy Hilly Catchments (CSHC) region within the Loess Plateau.

Table 1. Long-term hydrometeorological characteristics (1961-2011) and growing season leaf area index (LAI) (1982-2011) of the studied catchments in the Loess Plateau.

\begin{tabular}{|c|c|c|c|c|c|c|c|c|c|c|}
\hline \multirow[t]{2}{*}{ ID } & \multirow[t]{2}{*}{ Catchment } & \multirow[t]{2}{*}{ Gauging station } & \multirow{2}{*}{$\begin{array}{r}\text { Slope } \\
\left({ }^{\circ}\right)\end{array}$} & \multirow{2}{*}{$\begin{array}{c}\text { Area } \\
\left(\mathrm{km}^{2}\right)\end{array}$} & \multicolumn{6}{|c|}{ Annual average } \\
\hline & & & & & $\begin{array}{r}P \\
(\mathrm{~mm})\end{array}$ & $\begin{array}{r}Q \\
(\mathrm{~mm})\end{array}$ & $\begin{array}{r}\mathrm{SSY} \\
\left(\mathrm{t} \mathrm{km}^{-2}\right)\end{array}$ & $\begin{array}{r}\mathrm{SC} \\
\left(\mathrm{kg} \mathrm{m}^{-3}\right)\end{array}$ & $\begin{array}{r}C_{\mathrm{S}} \\
\left(\mathrm{t} \mathrm{km}^{-2}\right. \\
\left.\mathrm{mm}^{-1}\right)\end{array}$ & LAI \\
\hline 1 & Huangfu & Huangfu & 7.8 & 3175 & 388.95 & 36.34 & 11608.86 & 275.90 & 27.35 & 0.412 \\
\hline 2 & Gushan & Gaoshiya & 9.8 & 1263 & 422.49 & 49.55 & 12398.68 & 189.57 & 25.98 & 0.440 \\
\hline 3 & Kuye & Wenjiachuan & 6.3 & 8515 & 394.63 & 59.25 & 9099.60 & 114.99 & 21.17 & 0.427 \\
\hline 4 & Tuwei & Gaojiachuan & 5.8 & 3253 & 402.82 & 97.53 & 4454.47 & 38.44 & 10.16 & 0.406 \\
\hline 5 & Jialu & Shenjiawan & 10.4 & 1121 & 445.51 & 49.22 & 9645.19 & 142.19 & 20.03 & 0.480 \\
\hline 6 & Wuding & Baijiachuan & 6.8 & 29662 & 384.32 & 36.39 & 3089.61 & 74.09 & 7.67 & 0.460 \\
\hline 7 & Qingjian & Yanchuan & 15.9 & 3468 & 485.58 & 38.93 & 8747.17 & 190.57 & 17.35 & 0.626 \\
\hline 8 & Yanhe & Ganguyi & 16.5 & 5891 & 516.09 & 34.08 & 6604.90 & 166.31 & 12.45 & 0.920 \\
\hline 9 & Shiwang & Dacun & 15.2 & 2141 & 572.16 & 32.99 & 798.89 & 20.32 & 1.31 & 3.261 \\
\hline 10 & Qiushui & Linjiaping & 13.0 & 1873 & 469.02 & 34.83 & 7818.21 & 185.79 & 15.75 & 0.938 \\
\hline 11 & Sanchuan & Houdacheng & 14.6 & 4102 & 486.23 & 50.37 & 3444.56 & 53.39 & 6.63 & 1.887 \\
\hline 12 & Quchan & Peigou & 14.6 & 1023 & 539.73 & 30.24 & 7492.57 & 192.01 & 13.68 & 0.934 \\
\hline 13 & Xinshui & Daning & 14.0 & 3992 & 529.96 & 29.22 & 3004.96 & 86.81 & 5.23 & 1.752 \\
\hline 14 & Zhouchuan & Jixian & 15.3 & 436 & 530.06 & 30.13 & 4951.15 & 107.99 & 8.55 & 1.165 \\
\hline 15 & CSHC & $\begin{array}{l}\text { Toudaoguai and } \\
\text { Longmen }\end{array}$ & 10.5 & 129654 & 437.27 & 33.30 & 3988.04 & 102.42 & 8.73 & 0.765 \\
\hline
\end{tabular}



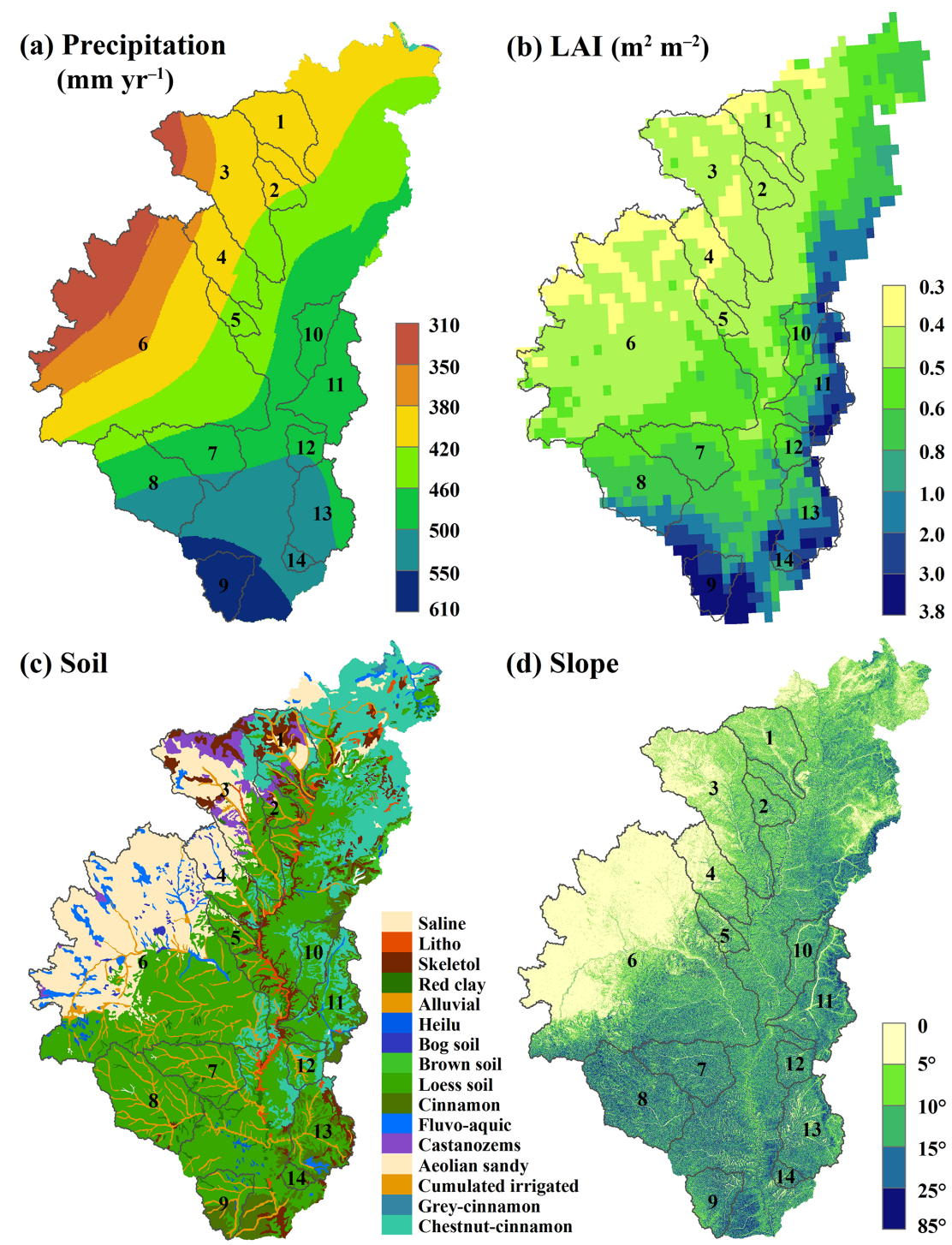

Figure 2. Spatial distribution of (a) annual precipitation (1961-2011), (b) growing season leaf area index (LAI, 1982-2011), (c) soil type, and (d) slope in the study area.

\section{Materials and methods}

\subsection{Study area}

The CSHC region covers the area between the Toudaoguai and Longmen hydrological stations in the main stream of the YR (Fig. 1). The main stream that flows through the CSHC region is $733 \mathrm{~km}$ long and its drainage catchment covers $12.97 \times 10^{4} \mathrm{~km}^{2}$, which accounts for $14.8 \%$ of the entire YR Basin. The CSHC region is characterized by arid to semi-arid climate conditions. The annual precipitation in the region during 1961-2011 was $437 \mathrm{~mm}$ on average, and varied from lower than $300 \mathrm{~mm}$ in the northwest to $580 \mathrm{~mm}$ in the southeast (McVicar et al., 2007). The precipitation that occurs during the flood season (June-September) is usually in the form of rainstorms with high intensity and accounts for $72 \%$ of the annual rainfall total. Correspondingly, about $45 \%$ of the annual runoff and $88 \%$ of the annual sediment yield within the region are produced during the flood season. The northwestern part of the CSHC is relatively flat, while the southeastern part is more finely dissected (Rustomji et al., 2008).

Fourteen main catchments along a north-south transect within the CSHC study area were chosen for the study (Fig. 1). These catchments account for $57.4 \%$ of the CSHC area, and contribute about 70 and $72 \%$ of the streamflow and sediment load of the overall CSHC, respectively, based on observed hydrological data during 1961-2011 (Rustomji et al., 2008; Yao et al., 2011). Characteristics of these catchments are presented in Table 1 and Fig. 2, showing that the catchments present strong climate and land sur- 


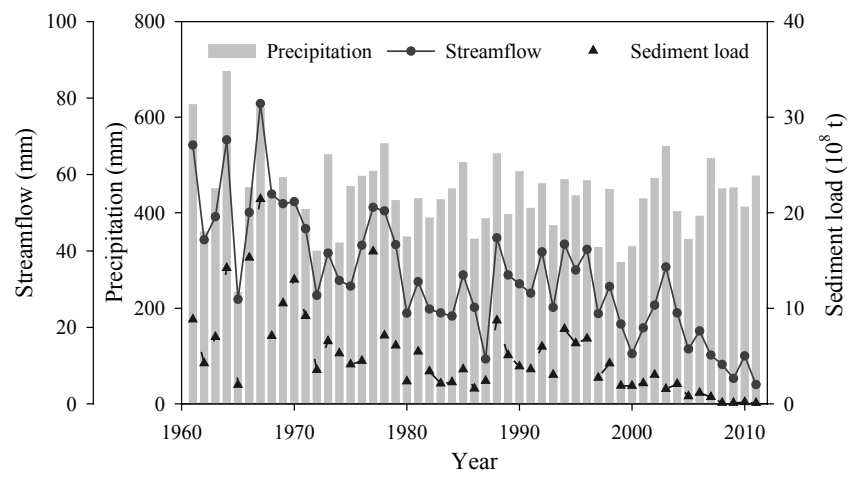

Figure 3. Annual precipitation, streamflow, and sediment load for the whole CSHC region during 1961-2011.

face gradients. The catchments in the northwestern part (nos. 1-6) had relatively lower mean annual precipitation ( $380 \mathrm{~mm}<\bar{P}<445 \mathrm{~mm}$, where $\bar{P}$ is mean annual precipitation over 1961-2011) and a low growing season (AprilOctober) LAI $(0.41<\mathrm{LAI}<0.48$, where LAI is the leaf area index), while the corresponding values for catchments in the southeastern part (nos. 7-14) were $470-570 \mathrm{~mm}$ and $0.63<\mathrm{LAI}<3.26$, respectively.

The entire CSHC region is considered as an additional "catchment", and it is also examined independently. The streamflow and sediment load for the whole region were taken to be equal to the differences of corresponding measurements between the Toudaoguai and Longmen gauging stations. The average annual precipitation, streamflow, and sediment load of the region during 1961-2011 were $437.27 \mathrm{~mm}, 33.30 \mathrm{~mm}$ and $5.17 \mathrm{Gt}$, respectively. Both the annual river discharge and sediment load across the region showed significant decreasing trends $\left(-0.82 \mathrm{~mm} \mathrm{yr}^{-1}\right.$, $p<0.001$ and $-0.19 \mathrm{Gt} \mathrm{yr}^{-1}, p<0.001$, respectively) over the past 5 decades, whereas precipitation decreased only slightly ( $-0.93 \mathrm{~mm} \mathrm{yr}^{-1}, p=0.25$ ) (Fig. 3).

\subsection{Data collection}

Monthly streamflow and sediment load data during 19612011 were provided by the Yellow River Conservancy Commission of China. Daily rainfall data from 1961 to 2011 at 66 meteorological stations in and around the region (Fig. 1) were obtained from the National Meteorological Information Center of China. The spatial average of rainfall data was calculated using the co-kriging interpolation algorithm with the DEM as an additional input. The hydro-meteorological data (including annual precipitation, $P(\mathrm{~mm})$, streamflow, $Q(\mathrm{~mm})$, and sediment load, $S(\mathrm{t}))$, specific sediment yield defined as $\mathrm{SSY}=S / A\left(\mathrm{t} \mathrm{km}^{-2}\right)$, where $A$ is the drainage area of the hydrological station $\left(\mathrm{km}^{2}\right)$, sediment concentration defined as $\mathrm{SC}=S /(Q \times A)\left(\mathrm{kg} \mathrm{m}^{-3}\right)$, and the sediment coefficient defined as $C_{\mathrm{s}}=\mathrm{SSY} / P\left(\mathrm{t} \mathrm{km}^{-2} \mathrm{~mm}^{-1}\right)$ were estimated for each catchment.
The mean catchment slope gradient based on the ASTER GDEM data with a resolution of $30 \mathrm{~m}$ and soil data (scale $1: 500000$ ) were provided by the National Earth System Science Data Sharing Infrastructure (http://www.geodata.cn). The land use information as at 1975, 1990, 2000, and 2010 was determined with Landsat MSS and TM remote sensing images at a spatial resolution of $30 \mathrm{~m}$. Six land use types were classified, i.e., forestland, cropland, grassland, construction land, water body, and barren land. The LAI data during 1982-2011 were obtained from the Global Land Surface Satellite (GLASS) NDVI Series with a spatial resolution of $1 \mathrm{~km}$ (www.landcover.org, Zhao et al., 2013). The total areas impacted by various SWCMs (i.e., afforestation, grass plantation, terraces, and check-dams) in each catchment during the 1960s-2000s were obtained from Yao et al. (2011).

\subsection{Trend test}

The non-parametric Mann-Kendall (M-K) test method proposed by Mann (1945) and Kendall (1975) was used to determine the significance of the trends in annual meteorological and hydrological time series. A precondition for using the MK test is to remove the serial correlation of climatic and hydrological series. In this study, the trend-tree pre-whitening (TFPW) method of Yue and Wang (2002) was used to remove the auto-correlations before the trend test. There was no residual autocorrelation remaining after performing the TFPW. A $Z$-statistic was obtained from the $\mathrm{M}-\mathrm{K}$ test on the whitened series. A negative value of $Z$ indicates a decreasing trend, and vice versa. The magnitude of the slope of the trend $(\beta)$ was estimated by (Sen, 1968; Hirsch et al., 1982)

$\beta=\operatorname{median}\left[\frac{x_{j}-x_{i}}{j-i}\right]$ for all $i<j$,

where $x_{i}$ and $x_{j}$ are the sequential data values in periods $i$ and $j$, respectively.

\subsection{Attribution analysis of changes in sediment yield}

The time-trend analysis method was used to determine the quantitative contributions of LUCC and precipitation variability to sediment yield changes. This method is primarily designed to determine the differences in hydrological time series between different periods (reference and validation periods) with different LUCC conditions (Zhang et al., 2011). In this method, a regression equation between precipitation and sediment yield is developed and evaluated during the reference period, and the established equation is then used to estimate sediment yield during the validation period. The difference between measured and predicted sediment yields during the validation period represents the effects of LUCC, and the residual changes are caused by precipitation variability. The governing equations of the time-trend analysis 


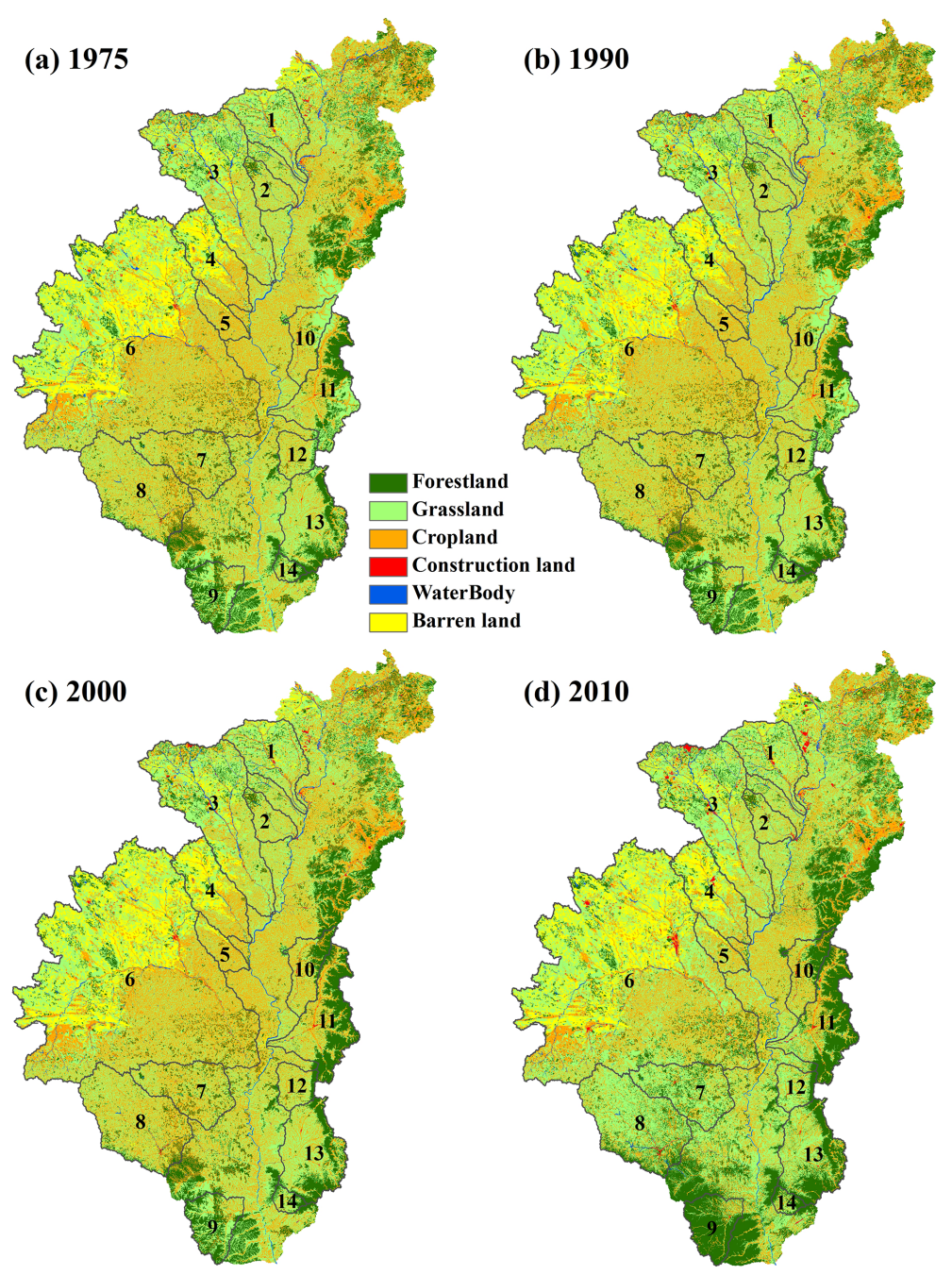

Figure 4. Land use and cover of the study area in (a) 1975, (b) 1990, (c) 2000, and (d) 2010.

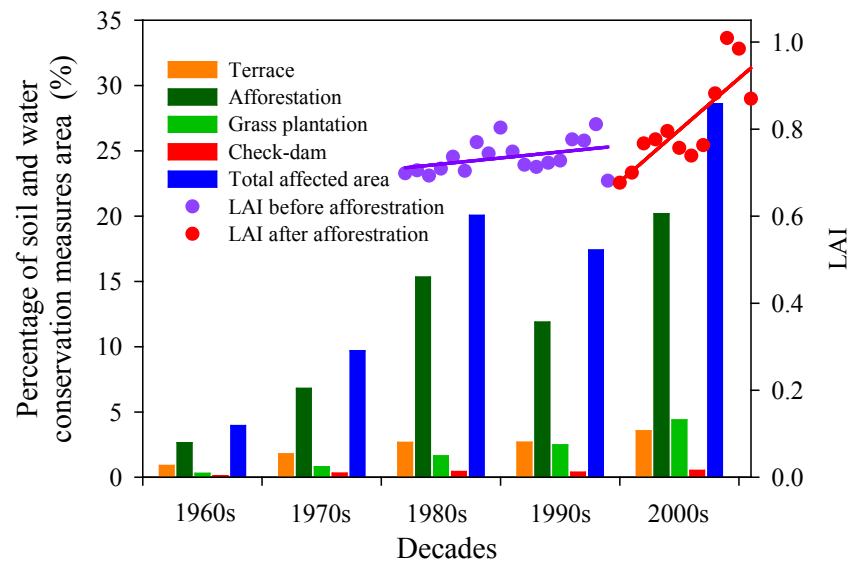

Figure 5. The changes in soil and water conservation measures area and growing season LAI in the study area. method can be expressed as

$$
\begin{aligned}
& \mathrm{SSY}_{1}=f\left(P_{1}\right), \\
& \mathrm{SSY}_{2}^{\prime}=f\left(P_{2}\right), \\
& \Delta \mathrm{SSY}^{\mathrm{LUCC}}=\overline{\mathrm{SSY}_{2}}-\overline{\mathrm{SSY}_{2}^{\prime}}, \\
& \Delta \mathrm{SSY}^{\mathrm{Pre}}=\left(\overline{\mathrm{SSY}_{2}}-\overline{\mathrm{SSY}_{1}}\right)-\Delta \mathrm{SSY}^{\mathrm{LUCC}},
\end{aligned}
$$

where $\mathrm{SSY}^{\prime}$ is the predicted sediment yield, and subscripts 1 and 2 indicate the reference and validation periods, respectively. $\overline{\mathrm{SSY}_{1}}$ and $\overline{\mathrm{SSY}_{2}}$ represent mean measured sediment yield during the reference and validation periods, respectively, and $\overline{\mathrm{SSY}_{2}^{\prime}}$ represents mean predicted sediment yield during the validation period. $\triangle S S Y^{\mathrm{LUCC}}$ and $\triangle \mathrm{SSY} \mathrm{Pre}^{\mathrm{Pre}}$ are sediment yield changes during the validation period associated with LUCC and precipitation variability, respectively. Rustomji et al. (2008) found that the square root of annual sediment yield in the catchments of the Loess Plateau was linearly related to annual precipitation. This was, therefore, used in this study as the motivation to develop the 
precipitation-sediment yield relationship during the reference period:

$\sqrt{\mathrm{SSY}}=a P+b$.

In this study, the full data period of 1961-2011 was divided into three phases (1961-1969, 1970-1999, and 20002011). The first period was considered the reference period as the effects of human activities were slight and could be ignored (Wang et al., 2016). During the second stage, numerous SWCMs were implemented. For the third stage, a large ecological restoration campaign (the GFG project) was launched in 1999.

\section{Results and discussion}

\subsection{Changes in land use/cover}

The CSHC region has undergone extensive LUCC caused by the implementation of SWCM and vegetation restoration projects (e.g., the GFG project). Figure 4 shows the distribution of land use types of the region in 1975, 1990, 2000, and 2010. More than $90 \%$ of the whole area was occupied by the cropland, forestland, and grassland. The area of cropland decreased by $26.72 \%$ and forestland increased by $53.15 \%$, and there was no significant change for the area of grassland (increase of $4.21 \%$ ) in the CSHC region from 1975 to 2010. The majority of changes occurred during 2000-2010 due to the GFG (reforestation) project (26.67\% decrease and $36.21 \%$ increase for cropland and forestland, respectively). The transition from cropland to forestland was greater in the catchments of the southeastern part (especially in catchment nos. 7-9) than that in the northwestern part (Fig. 4). In the period 1975-2000, the increase in forestland was 26.34 and $4.55 \%$ in the southeastern and northwestern parts, respectively, and the change in cropland was negligible (only -0.39 and $0.22 \%$, respectively). During 2000-2010, the forestland increased by 47.79 and $18.30 \%$, and the cropland decreased by 44.84 and $21.04 \%$ in the southeastern and northwestern parts, respectively.

The SWCMs implemented in the LP included both biotic treatments (e.g., afforestation and grass-planting) and engineering measures (e.g., construction of terrace and check-dam and gully control projects). Afforestation, grassplanting, and construction of terraces were seen as the slope measures, while building of check-dams and gully control projects were the measures on the river channel. Although the area utilized for engineering measures was much smaller than the biotic treatments, they immediately and substantially trap streamflow and sediment load. The fraction of the treated area (area treated by erosion control measures relative to total catchment area) increased from $3.95 \%$ in the 1960 s to $28.61 \%$ in the 2000s (Fig. 5). The increase in the treated area was greatest during the 1980s as a result of comprehensive management of small watersheds and the 2000 s due to the GFG project since 1999. Some decreases in SWCM areas (i.e., afforestation and check-dams) occurred during the 1990s (Fig. 5) as some planted trees died due to drought and some small and medium check-dams were fully deposited by sediment and then subsequently destroyed by floods.

The growing season LAI of the whole region changed from 0.74 during 1982-1999 to 0.81 during 2000-2011, an increase of $10.16 \%$ (Fig. 5). The LAI did not show a significant increase during 1982-1999 $\left(0.003 \mathrm{yr}^{-1}, p=0.11\right)$, and it increased significantly during 2000-2011 $\left(0.024 \mathrm{yr}^{-1}\right.$, $p<0.01$ ). The increase in growing season LAI during 19822011 was greater for the catchments in the southeastern part $\left(0.009 \mathrm{yr}^{-1}\right)$ compared to the northwestern part $\left(0.004 \mathrm{yr}^{-1}\right)$, especially after 2000 (Fig. 6). In the period from 1982-1999 to 2000-2011, the average increase in growing LAI of the 14 sub-catchments was $0.088 \mathrm{yr}^{-1}\left(0.010-0.183 \mathrm{yr}^{-1}\right)$, with increases of 0.114 and $0.053 \mathrm{yr}^{-1}$ in the southeastern and northwestern parts, respectively.

\subsection{Trends of hydro-meteorological and sediment yield variables}

Table 2 shows the trends in annual $P, Q$, SSY, SC, and $C_{\mathrm{s}}$ of the 15 catchments during the period 1961-2011. The annual $P$ showed a declining trend in all catchments except the Jialu catchment, but the changing trend is only significant in the Xinshui and Zhouchuan catchments $(p<0.05)$. The annual $Q, \mathrm{SSY}, \mathrm{SC}$, and $C_{\mathrm{s}}$ showed significant decreasing trends in all the catchments, and most of the decreases were at the 0.001 significance level. For the 14 sub-catchments, the average decrease rates of annual values of $Q, \mathrm{SSY}, \mathrm{SC}$, and $C_{\mathrm{s}}$ were $0.86 \mathrm{~mm} \mathrm{yr}^{-1} \quad\left(0.24-1.66 \mathrm{~mm} \mathrm{yr}^{-1}\right), \quad 190.06 \mathrm{t} \mathrm{km}^{-2} \mathrm{yr}^{-1}$ $\left(26.47-398.82 \mathrm{t} \mathrm{km}^{-2} \mathrm{yr}^{-1}\right), \quad 2.73 \mathrm{~kg} \mathrm{~m}^{-3} \mathrm{yr}^{-1} \quad(0.69$ $\left.4.70 \mathrm{~kg} \mathrm{~m}^{-3} \mathrm{yr}^{-1}\right)$, and $0.38 \mathrm{t} \mathrm{km}^{-2} \mathrm{~mm}^{-1} \mathrm{yr}^{-1} \quad(0.04$ $0.87 \mathrm{t} \mathrm{km}^{-2} \mathrm{~mm}^{-1} \mathrm{yr}^{-1}$ ), respectively. The changing rates of $Q, \mathrm{SSY}, \mathrm{SC}$, and $C_{\mathrm{s}}$ for the whole region were $-0.85 \mathrm{~mm} \mathrm{yr}^{-1},-131.52 \mathrm{t} \mathrm{km}^{-2} \mathrm{yr}^{-1},-2.06 \mathrm{~kg} \mathrm{~m}^{-3} \mathrm{yr}^{-1}$, and $-0.27 \mathrm{t} \mathrm{km}^{-2} \mathrm{~mm}^{-1} \mathrm{yr}^{-1}$, respectively. The annual average reductions in the whole region were equivalent to $2.56,3.30,2.01$, and $3.07 \%$ of the mean annual values of $Q$, SSY, SC, and $C_{\mathrm{s}}$, respectively.

The mean and the coefficient of variation, $C_{\mathrm{v}}$, representing inter-annual variability of annual values of $P, Q$, SSY, $\mathrm{SC}$, and $C_{\mathrm{S}}$ for the 15 catchments during the three phases (reference period-1, period-2, and period-3) are shown in Fig. 7. Compared to standard deviation, the $C_{\mathrm{v}}$ value was better able to indicate the inter-annual variability of precipitation, streamflow, and sediment load among the catchments with distinctly different average values. Compared to the reference period, the mean annual precipitation decreased by $11.73 \%(6.36-15.69 \%)$ and $10.64 \%(5.88-16.7 \%)$ on average in period-2 and period-3, respectively. From period- 2 to period-3, the change in mean annual precipitation was slight (increased by $1.32 \%$ on average) with a decrease of 2.45 


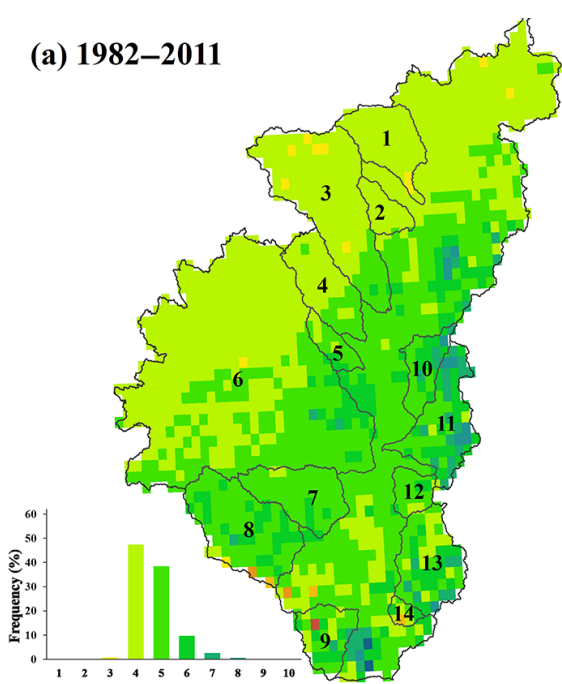

LAI Trend $\left(\mathrm{m}^{2} \mathbf{m}^{-2} \mathbf{y r}^{1}\right)$

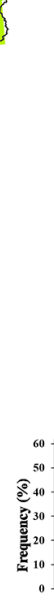

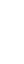

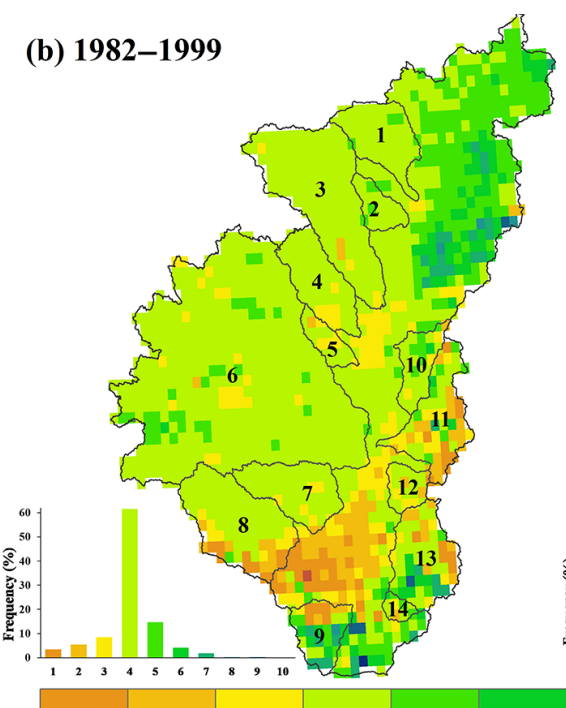

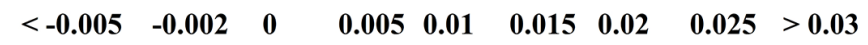

(c) 2000-2011
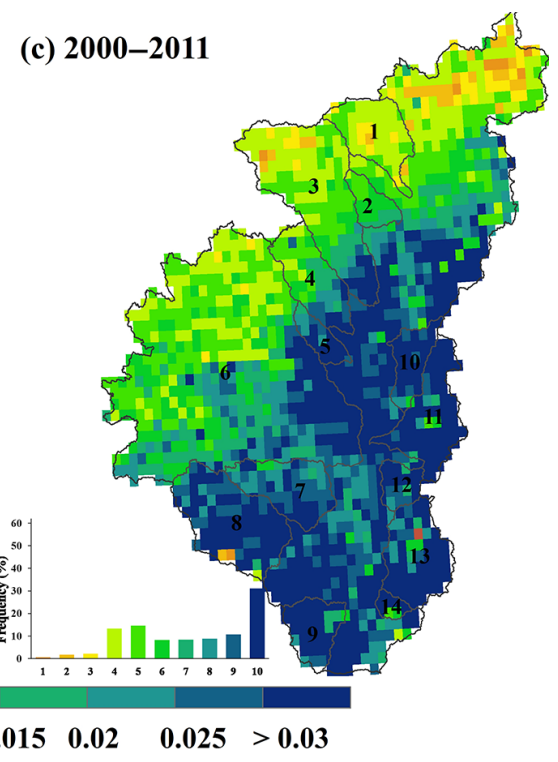

Figure 6. Long-term trends in growing season LAI changes over (a) 1982-2011, (b) 1982-1999, and (c) 2000-2011 in the study area. The inset in each figure shows the frequency distribution of the LAI trends.

Table 2. Mann-Kendall trend analysis results for the annual precipitation $(P)$, streamflow $(Q)$, specific sediment yield (SSY), sediment concentration (SC), and sediment coefficient $\left(C_{\mathrm{S}}\right)$ during 1961-2011.

\begin{tabular}{|c|c|c|c|c|c|c|c|c|c|c|c|}
\hline \multirow[t]{2}{*}{ ID } & \multirow[t]{2}{*}{ Catchment } & \multicolumn{2}{|c|}{$P$} & \multicolumn{2}{|c|}{$Q$} & \multicolumn{2}{|c|}{ SSY } & \multicolumn{2}{|c|}{$\mathrm{SC}$} & \multicolumn{2}{|c|}{$C_{\mathrm{s}}$} \\
\hline & & $Z$ & $\begin{array}{r}\beta \\
\left(\mathrm{mm} \mathrm{yr}^{-1}\right)\end{array}$ & $Z$ & $\begin{array}{r}\beta \\
\left(\mathrm{mm} \mathrm{yr}^{-1}\right)\end{array}$ & $Z$ & $\begin{array}{r}\beta\left(\mathrm{t} \mathrm{km}^{-2}\right. \\
\left.\mathrm{yr}^{-1}\right)\end{array}$ & $Z$ & $\begin{array}{r}\beta\left(\mathrm{kg} \mathrm{m}^{-3}\right. \\
\left.\mathrm{yr}^{-1}\right)\end{array}$ & $Z$ & $\begin{array}{r}\beta\left(\mathrm{t} \mathrm{km}^{-2}\right. \\
\left.\mathrm{mm}^{-1} \mathrm{yr}^{-1}\right)\end{array}$ \\
\hline 1 & Huangfu & $-0.57^{\mathrm{ns}}$ & -0.52 & $-4.82^{* * *}$ & -0.99 & $-4.50^{* * *}$ & -323.24 & $-1.97^{*}$ & -2.58 & $-4.71^{* * *}$ & -0.80 \\
\hline 2 & Gushan & $-0.78^{\mathrm{ns}}$ & -1.16 & $-5.02^{* * *}$ & -1.47 & $-4.90^{* * *}$ & -398.82 & $-3.75^{* * *}$ & -3.92 & $-5.15^{* * *}$ & -0.87 \\
\hline 3 & Kuye & $-0.49^{\mathrm{ns}}$ & -0.37 & $-5.98^{* * *}$ & -1.66 & $-5.41^{* * *}$ & -288.83 & $-4.61^{* * *}$ & -3.22 & $-5.60^{* * *}$ & -0.63 \\
\hline 4 & Tuwei & $-0.24^{\mathrm{ns}}$ & -0.27 & $-7.88^{* * *}$ & -1.57 & $-5.20^{* * *}$ & -130.34 & $-4.37^{* * *}$ & -0.98 & $-5.59^{* * *}$ & -0.30 \\
\hline 5 & Jialu & $0.19^{\mathrm{ns}}$ & 0.26 & $-7.55^{* * *}$ & -1.42 & $-5.36^{* * *}$ & -298.10 & $-3.80^{* * *}$ & -3.89 & $-5.60^{* * *}$ & -0.69 \\
\hline 6 & Wuding & $-0.39^{\mathrm{ns}}$ & -0.37 & $-6.60^{* * *}$ & -0.54 & $-4.55^{* * *}$ & -79.19 & $-3.33^{* * *}$ & -1.35 & $-4.94^{* * *}$ & -0.20 \\
\hline 7 & Qingjian & $-0.73^{\mathrm{ns}}$ & -0.56 & $-2.06^{*}$ & -0.24 & $-3.01^{* *}$ & -138.54 & $-3.09^{* *}$ & -3.53 & $-2.73^{* *}$ & -0.30 \\
\hline 8 & Yanhe & $-1.19^{\mathrm{ns}}$ & -1.17 & $-3.22^{* *}$ & -0.34 & $-3.36^{* * *}$ & -115.18 & $-3.30^{* * *}$ & -3.07 & $-3.10^{* *}$ & -0.22 \\
\hline 9 & Shiwang & $-1.20^{\mathrm{ns}}$ & -1.50 & $-4.01^{* * *}$ & -0.61 & $-6.26^{* * *}$ & -26.47 & $-5.43^{* * *}$ & -0.69 & $-6.12^{* * *}$ & -0.04 \\
\hline 10 & Qiushui & $-0.28^{\mathrm{ns}}$ & -0.35 & $-5.80^{* * *}$ & -0.97 & $-6.98^{* * *}$ & -290.44 & $-5.00^{* * *}$ & -4.00 & $-5.98^{* * *}$ & -0.55 \\
\hline 11 & Sanchuan & $-1.43^{\mathrm{ns}}$ & -1.71 & $-6.09^{* * *}$ & -0.96 & $-5.35^{* * *}$ & -108.69 & $-5.13^{* * *}$ & -1.60 & $-5.99^{* * *}$ & -0.21 \\
\hline 12 & Quchan & $-0.94^{\mathrm{ns}}$ & -1.14 & $-3.23^{* *}$ & -0.42 & $-3.65^{* * *}$ & -173.16 & $-3.72^{* * *}$ & -4.12 & $-3.46^{* * *}$ & -0.29 \\
\hline 13 & Xinshui & $-2.37^{*}$ & -2.71 & $-5.57^{* * *}$ & -0.70 & $-5.92^{* * *}$ & -106.30 & $-3.77^{* * *}$ & -1.92 & $-5.60^{* * *}$ & -0.19 \\
\hline 14 & Zhouchuan & $-2.21^{*}$ & -2.48 & $-7.20^{* * *}$ & -0.79 & $-5.86^{* * *}$ & -183.49 & $-6.73^{* * *}$ & -4.70 & $-7.12^{* * *}$ & -0.35 \\
\hline 15 & CSHC & $-0.67^{\mathrm{ns}}$ & -0.55 & $-5.91^{* * *}$ & -0.85 & $-5.70^{* * *}$ & -131.52 & $-4.26^{* * *}$ & -2.06 & $-5.67^{* * *}$ & -0.27 \\
\hline
\end{tabular}

***, ${ }^{* *}$, and ${ }^{*}$ indicate the significance levels of $0.001,0.01$, and 0.05 , respectively. ${ }^{n s}$ indicates the significance levels exceeding 0.05 .

$5.87 \%$ in four catchments and an increase in the remaining catchments $(0.35-8.29 \%)$. The variability of annual $P$ also decreased as indicated by the reductions of $C_{\mathrm{V}}$ values during period-2 and period-3 (Fig. 7a). In contrast to annual $P$, the reductions of mean annual $Q, \mathrm{SSY}, \mathrm{SC}$, and $C_{\mathrm{S}}$ were clearly more evident. With respect to the reference period, the reduction was $34.41 \%(9.45-54.72 \%), 48.02 \%(17.98-67.61 \%)$, $24.20 \%(-9.93-47.77 \%)$, and $39.31 \%(4.64-63.5 \%)$ for $Q, \mathrm{SSY}, \mathrm{SC}$, and $C_{\mathrm{s}}$ during period-2, and the decreasing rate was even more in period-3, with values of $64.82 \%$ (36.72-84.19\%), 88.23\% (64.94-97.64\%), $67.81 \%$ (17.28-
$91.12 \%)$, and $85.85 \%$ (63.51-96.97\%), respectively. $C_{\mathrm{v}}$ of annual $Q$ increased in eight catchments, with the remaining ones showing decreasing trends (Fig. 7b), while $C_{\mathrm{v}}$ values for SSY, SC, and $C_{\mathrm{s}}$ increased in all catchments (Fig. $7 \mathrm{c}-\mathrm{e}$ ). The above results indicate substantially different behaviors of the changes among precipitation, streamflow, and sediment load.

\subsection{Quantitative attribution of sediment yield decline}

The effects of precipitation change and LUCC on sediment yield reductions in period- 2 and period- 3 were quantified us- 

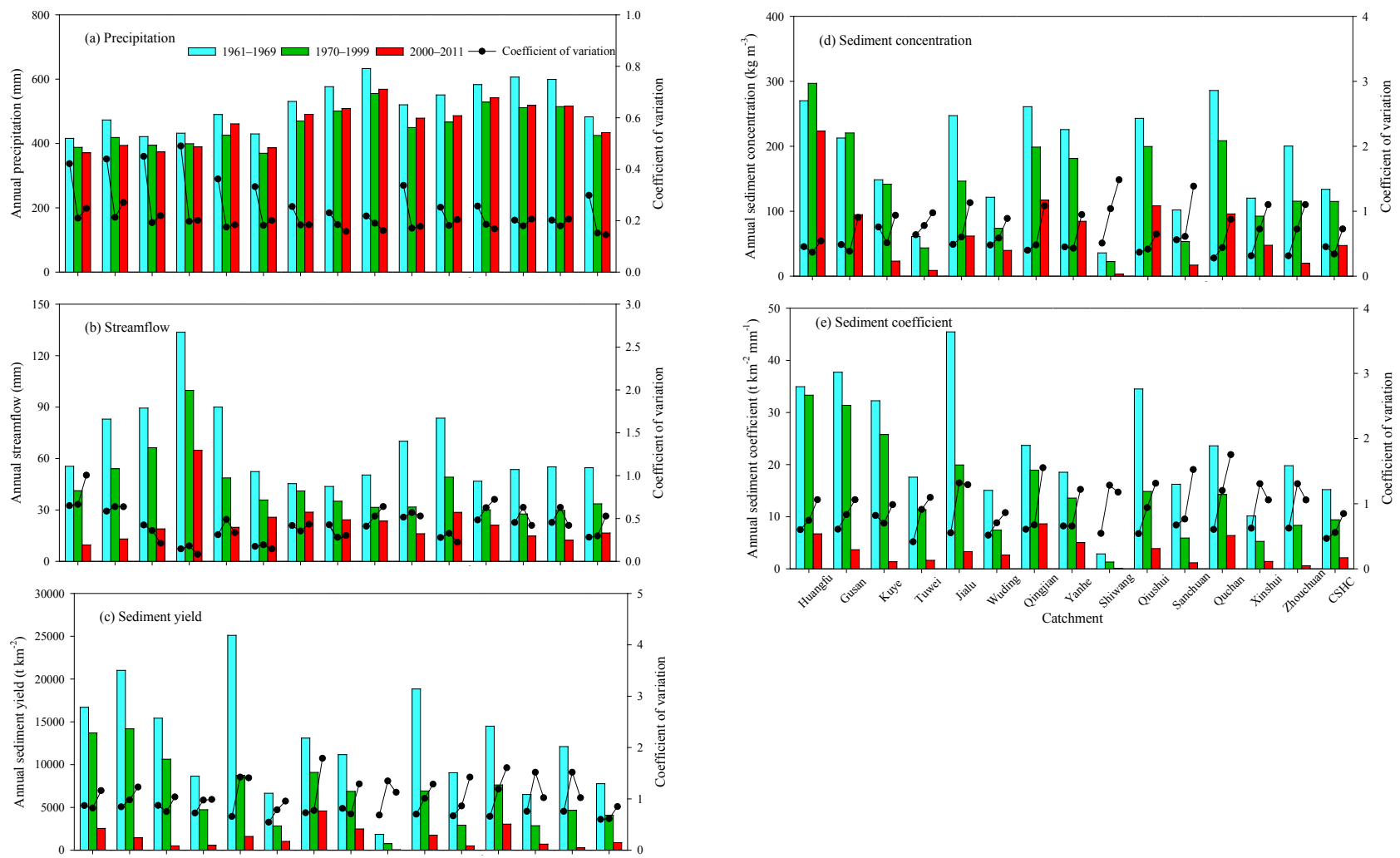

Figure 7. The changes in (a) precipitation, (b) streamflow, (c) sediment yield, (d) sediment concentration, and (e) sediment coefficient during different stages (1961-1969, 1970-1999, and 2000-2011).

Table 3. The linear regression equations between the square root of specific sediment yield and annual precipitation $(\sqrt{\mathrm{SSY}}=a P+b)$ during three stages (1961-1969, 1970-1999, and 2000-2011).

\begin{tabular}{|c|c|c|c|c|c|c|c|c|c|c|}
\hline \multirow[t]{2}{*}{ ID } & \multirow[t]{2}{*}{ Catchment } & \multicolumn{3}{|c|}{ Reference period (1961-1969) } & \multicolumn{3}{|c|}{ Period-2 (1970-1999) } & \multicolumn{3}{|c|}{ Period-3 (2000-2011) } \\
\hline & & Regression equation & $R^{2}$ & $p$ & Regression equation & $R^{2}$ & $p$ & Regression equation & $R^{2}$ & \\
\hline 1 & Huangfu & $y=0.341 x+12.041$ & 0.78 & 0.002 & $y=0.397 x-11.454$ & 0.40 & 0.000 & $y=0.135 x+5.842$ & 0.12 & 0.277 \\
\hline 2 & Gushan & $y=0.349 x+8.237$ & 0.84 & 0.001 & $y=0.354 x-5.627$ & 0.37 & 0.000 & $y=0.076 x+10.415$ & 0.09 & 0.344 \\
\hline 3 & Kuye & $y=0.323 x+9.939$ & 0.67 & 0.007 & $y=0.325 x-3.904$ & 0.35 & 0.001 & $y=0.037 x+8.208$ & 0.03 & 0.564 \\
\hline 4 & Tuwei & $y=0.218 x+12.635$ & 0.87 & 0.000 & $y=0.188 x+1.648$ & 0.22 & 0.008 & $y=-0.030 x+27.644$ & 0.03 & 0.613 \\
\hline 5 & Jialu & $y=0.382 x+6.976$ & 0.78 & 0.004 & $y=0.222 x+11.867$ & 0.13 & 0.049 & $y=0.072 x+7.131$ & 0.03 & 0.616 \\
\hline 6 & Wuding & $y=0.174 x+20.544$ & 0.53 & 0.027 & $y=0.151 x+7.546$ & 0.26 & 0.004 & $y=0.107 x-1.511$ & 0.17 & 0.182 \\
\hline 7 & Qingjian & $y=0.232 x+20.923$ & 0.48 & 0.040 & $y=0.173 x+29.319$ & 0.16 & 0.027 & $y=0.096 x+8.344$ & 0.05 & 0.522 \\
\hline 8 & Yanhe & $y=0.243 x+0.741$ & 0.39 & 0.070 & $y=0.126 x+32.699$ & 0.16 & 0.031 & $y=0.006 x+39.338$ & 0.00 & 0.973 \\
\hline 9 & Shiwang & $y=0.070 x+10.935$ & 0.27 & 0.150 & $y=0.079 x-7.837$ & 0.24 & 0.006 & $y=-0.007 x+9.426$ & 0.01 & 0.769 \\
\hline 10 & Qiushui & $y=0.257 x+30.738$ & 0.60 & 0.014 & $y=0.239 x-2.814$ & 0.29 & 0.002 & $y=-0.111 x+72.39$ & 0.06 & 0.448 \\
\hline 11 & Sanchuan & $y=0.191 x+15.053$ & 0.36 & 0.089 & $y=0.174 x-9.652$ & 0.42 & 0.000 & $y=-0.056 x+37.680$ & 0.06 & 0.432 \\
\hline 12 & Quchan & $y=0.202 x+34.590$ & 0.72 & 0.016 & $y=0.132 x+29.685$ & 0.09 & 0.104 & $y=-0.199 x+119.247$ & 0.11 & 0.300 \\
\hline 13 & Xinshui & $y=0.202 x-6.593$ & 0.71 & 0.004 & $y=0.184 x-17.464$ & 0.53 & 0.000 & $y=0.015 x+16.822$ & 0.01 & 0.823 \\
\hline 14 & Zhouchuan & $y=0.207 x+20.226$ & 0.33 & 0.090 & $y=0.245 x-31.399$ & 0.32 & 0.001 & $y=-0.035 x+26.145$ & 0.06 & 0.460 \\
\hline 15 & CSHC & $y=0.218 x+5.689$ & 0.70 & 0.005 & $y=0.174 x+2.912$ & 0.35 & 0.001 & $y=0.001 x+24.996$ & 0.00 & 0.994 \\
\hline
\end{tabular}

ing Eqs. (2)-(6) and the results are shown in Fig. 8. The form of Eq. (5) during the reference period is shown in Table 3. The analysis showed that both decreased precipitation and increased area treated with erosion control measures contributed to the observed sediment load reduction, and that LUCC played the major role. On average, LUCC and precipi- tation change contributed 74.39 and $25.61 \%$, respectively, to sediment load reduction from the reference period to period2 , with their respective contributions to sediment load reduction from the reference period to period-3 being 88.67 and $11.33 \%$. The effect of LUCC in period-3 was greater than in period-2 as the land use/cover (see Figs. 4-5) and vegeta- 

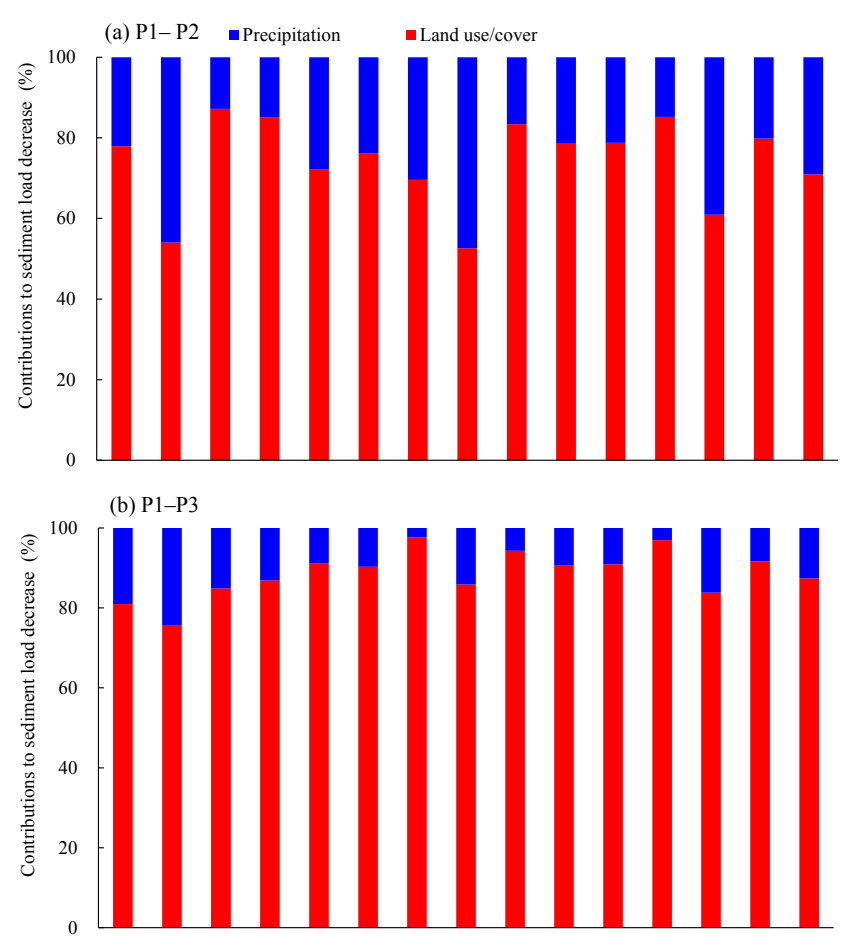

(c) P2-P3

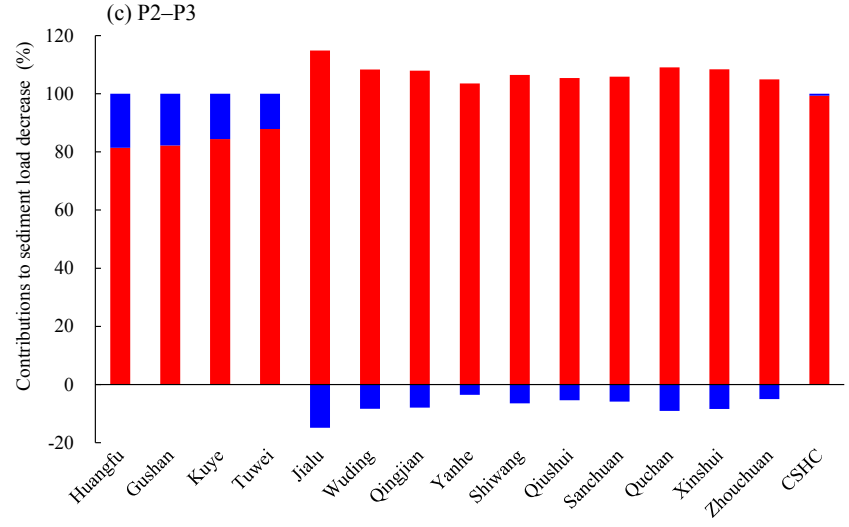

Figure 8. Contributions of precipitation and land use/cover to reductions of sediment load from (a) the reference period (P1) to period-2 (P2), (b) the reference period (P1) to period-3 (P3), and (c) period-2 (P2) to period-3 (P3).

tion coverage (see Fig. 6) had undergone substantial changes due to the ecological restoration campaigns launched during period-3. From period-2 to period-3, the contribution of precipitation was negative for sediment yield reduction in 11 catchments where the annual precipitation slightly increased, and thus the contribution of LUCC was larger than $100 \%$ (Fig. 8c). In the remaining four catchments, the average contribution of LUCC increased to $83.96 \%$.

In broad terms there are two factors that govern the annual sediment yield of a catchment: precipitation and landscape properties (soil, topography, and vegetation). Precipitation is the primary driver of runoff and, therefore, directly influences the sediment transport capacity of streamflow and sediment yield at the catchment scale. Higher precipitation means higher streamflow, which is the immediate driver of erosion and sediment transport. Landscape properties not only have an impact on the volume or intensity of streamflow, but also determine the erodibility of the soil. Correlations between the potential factors (precipitation, percentage area of afforestation, pasture plantation, terracing, check-dams and construction land, and LAI) and sediment yield change between different stages (see Table 4) showed that check-dam construction was the dominant factor for sediment yield reduction from the reference period to period-2. Pasture plantation and check-dam construction acted as the dominant factors for sediment yield from the reference period to period-3. The increase in precipitation mitigated the reduction of sediment yield to some degree from period-2 to period-3.

Based on the above results, the variation of SSY mainly depended on precipitation in the reference period before LUCC took effect and any spatial patterns of SSY in the catchments were controlled by differences in annual precipitation and land surface conditions. During the validation period (period-2 and period-3) when increased LUCC had taken effect, SSY decreased considerably. The decrease in precipitation was insignificant and LUCC contributed over $70 \%$ of the sediment yield reduction. In this case, the temporal changes in SSY depended more on the fraction of treated surface area, and precipitation possibly played a secondary role. The spatial pattern of the impacts of precipitation on sediment yield was dependent on the landscape properties among catchments. Guided by this framework, data were next analyzed to generate separate spatial and temporal patterns constituting respective components of the spatiotemporal patterns.

\subsection{Spatial-temporal pattern of the impacts of precipitation on sediment yield}

The regression equations of $\sqrt{\mathrm{SSY}}=a P+b$ are shown in Table 3. The spatial distributions of precipitation-sediment relationships during the three stages are shown in Fig. 9. During the reference period, the correlation between precipitation and sediment yield was significant in 11 catchments $(p<0.05)$ and the coefficient of determination $\left(R^{2}\right)$ ranged from 0.48 to 0.87 (Table 3 ). Furthermore, the precipitationsediment yield relationship varied from catchment to catchment and showed a spatial pattern. The correlation coefficient between precipitation and sediment yield was greater for catchments in the northwestern part, with an average $R^{2}$ value of 0.75 and a $p$ value of 0.007 compared to those in the southeastern part, where the average $R^{2}$ and $p$ values were 0.48 and 0.059 , respectively (Table 3 ). Based on the slopes of the regression equations between annual precipitation and sediment yield, the 14 catchments were classified into four groups (Group-1: $a>0.3$; Group-2: $0.2<a<0.3$; Group-3: $0.1<a<0.2$; and Group-4: $0<a<0.1$ ), which indicate that the sediment production capability of annual pre- 

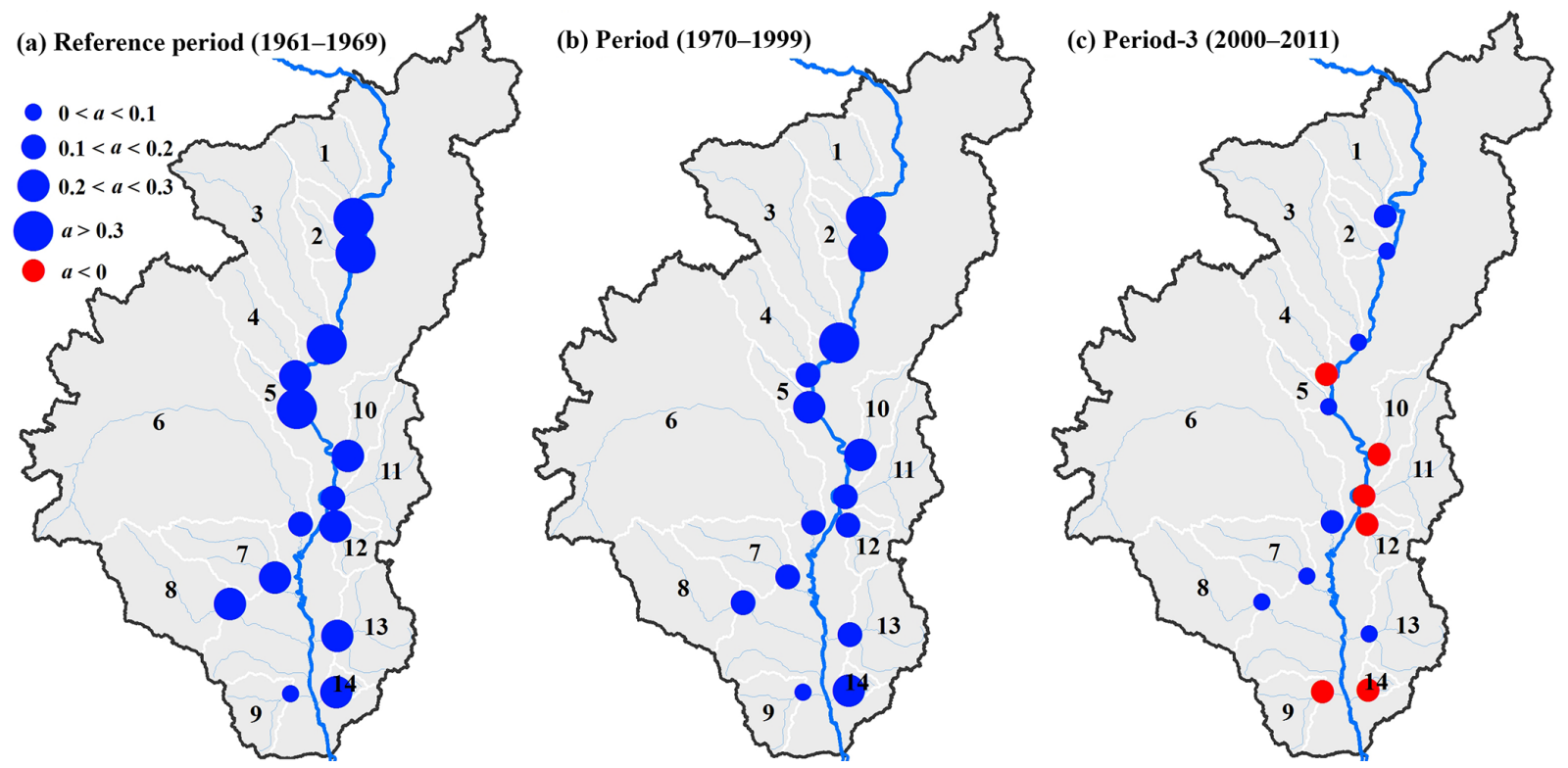

Figure 9. Spatial distribution of slope $a$ in the regression equation $\sqrt{\mathrm{SSY}}=a P+b$ during (a) the reference period (1961-1969), (b) period-2 (1970-1999), and (c) period-3 (2000-2011). SSY is the specific sediment yield, and $P$ is precipitation.

Table 4. The regression models for sediment yield change ( $\triangle \mathrm{SSY})$ in different stages.

\begin{tabular}{llrr}
\hline Period & Regression model & $R^{2}$ & $p$ \\
\hline Reference period vs. period-2 & $\Delta$ SSY $=-0.135-0.850 \times \Delta$ Dam & 0.886 & 0.000 \\
Reference period vs. period-3 & $\Delta$ SSY $=-0.067-0.659 \times \Delta$ Dam $-0.081 \times \Delta$ Pasture & 0.928 & 0.023 \\
Period-2 vs. period-3 & $\Delta$ SSY $=-0.105-0.488 \times \Delta$ Dam $+0.058 \times \Delta P-0.129 \times \Delta$ Pasture & 0.905 & 0.003 \\
\hline
\end{tabular}

$\Delta$ Dam and $\Delta$ Pasture are changes in percentage area of check-dams and pasture plantation, respectively. $\Delta P$ is changes in annual precipitation over the two compared periods.

cipitation is different among the catchments (Fig. 9a). The four catchments in the northwestern part (nos. 1-3 and 5) had the greatest regression slopes of $a>0.3$ (Group-1) and the Shiwang catchment had the lowest regression slope of 0.07 (Group-4). Most of the catchments in the southeastern part were in the second group of $0.2<a<0.3$. Overall, the regressed equations were significant for most of the catchments, and were suitable for estimating the relative contributions of LUCC and precipitation variability to sediment yield changes.

Compared to the reference period, the correlation between precipitation and sediment yield during period- 2 decreased in the catchments, as indicated by lower $R^{2}$ values in Table 3 . The slopes of the regression lines in the period- 2 decreased in most of the catchments with respect to the reference period, except in Huangfu, Gushan, and Kuye catchments, which increased slightly. Furthermore, the spatial patterns of the precipitation-sediment yield relationship during these two periods were somewhat different (Fig. 9a and b). From the reference period to period-2, Jialu catchment moved from Group-1 to Group-2 and five catchments moved from Group2 to Group-3.
During period-3, the correlation between precipitation and sediment yield was weaker compared to the reference period and period-2 (Table 3). The relationships between precipitation and sediment yield were not significant in all the catchments (Table 3). The slopes of the regression lines during period-3 decreased sharply (Table 3 ). Six catchments (five in the northwestern part and one in the southeastern part) had negative regression slopes (Fig. 9c). This result indicates that the sediment production capability of annual precipitation decreased greatly during period-3, and the increase in precipitation amount in some catchments did not lead to increased sediment yield. Furthermore, the spatial patterns of the precipitation-sediment relationship during period-3 were clearly different from those during the reference period and period-2 (compare Fig. 9c against Fig. 9a-b). There were only three groups, with two catchments having regression slopes of $0.1<a<0.2$, six catchments having regression slopes of $0.1<a<0.2$, and six catchments having negative regression slopes.

The aforementioned analysis of the precipitationsediment yield relationship in different periods clearly indicates that the impacts of precipitation on sediment yield 
Table 5. Regression equations between the decadal sediment coefficient and percentage of the area affected by soil and water conservation measures $\left(\overline{\mathrm{SC}}=-m A_{\mathrm{c}}+n\right)$ in the catchments.

\begin{tabular}{lllcr}
\hline ID & Catchment & Regression equation & $R^{2}$ & $p$ \\
\hline 1 & Huangfu & $y=-0.67 x+45.88$ & 0.85 & 0.025 \\
2 & Gushan & $y=-0.90 x+46.66$ & 0.82 & 0.034 \\
3 & Kuye & $y=-0.83 x+38.32$ & 0.89 & 0.017 \\
4 & Tuwei & $y=-0.48 x+19.94$ & 0.98 & 0.002 \\
5 & Jialu & $y=-1.20 x+53.20$ & 0.97 & 0.002 \\
6 & Wuding & $y=-0.31 x+16.92$ & 0.97 & 0.003 \\
7 & Qingjian & $y=-0.31 x+24.70$ & 0.48 & 0.193 \\
8 & Yanhe & $y=-0.26 x+18.54$ & 0.79 & 0.045 \\
9 & Shiwang & $y=-0.15 x+3.01$ & 0.87 & 0.020 \\
10 & Qiushui & $y=-0.87 x+35.69$ & 0.80 & 0.040 \\
11 & Sanchuan & $y=-0.28 x+13.32$ & 0.78 & 0.046 \\
12 & Quchan & $y=-0.29 x+21.02$ & 0.52 & 0.169 \\
13 & Xinshui & $y=-0.20 x+8.63$ & 0.72 & 0.069 \\
14 & Zhouchuan & $y=-0.61 x+17.89$ & 0.61 & 0.118 \\
15 & CSHC & $y=-0.54 x+17.74$ & 0.99 & 0.000 \\
\hline
\end{tabular}

declined with time. The impacts were different among catchments, with a clear spatial pattern. The effects of precipitation on the sediment yield were greater in the northwestern part compared to those in the southeastern part. The decreased effects of precipitation on sediment yield with time were consistent with the significant reductions of sediment coefficient (Table 2) and the decreased contribution of precipitation to sediment load reduction (25.61 and $11.33 \%$ in period-2 and period-3, respectively). During period-2, the LUCC were mainly induced by SWCM, especially engineering measures. During period-3, the combined effects of substantial vegetation cover and conservation measures further weakened the effects of precipitation on sediment load reduction.

\subsection{Spatial-temporal pattern of the impacts of land use/cover on sediment yield}

In order to quantify the effects of SWCM on sediment load reduction, the relationships between the decadal sediment coefficient and the fraction of area treated with erosion control measures in the 15 catchments were analyzed and the results are presented in Table 5. The decadal sediment coefficient $(\overline{\mathrm{SC}})$ decreased linearly with the fraction of treated land surface area $\left(A_{\mathrm{c}}\right)$ in all catchments:

$\overline{\mathrm{SC}}=-m A_{\mathrm{c}}+n$.

The correlations were significant in 11 catchments ( $p<0.05$ ), with $R^{2}$ ranging from 0.78 to 0.99 (Table 5). The effects of SWCM on sediment load change show a spatial pattern. The correlation between sediment coefficients and conservation measures were stronger in catchments located in the northwestern part compared to that in the southeastern

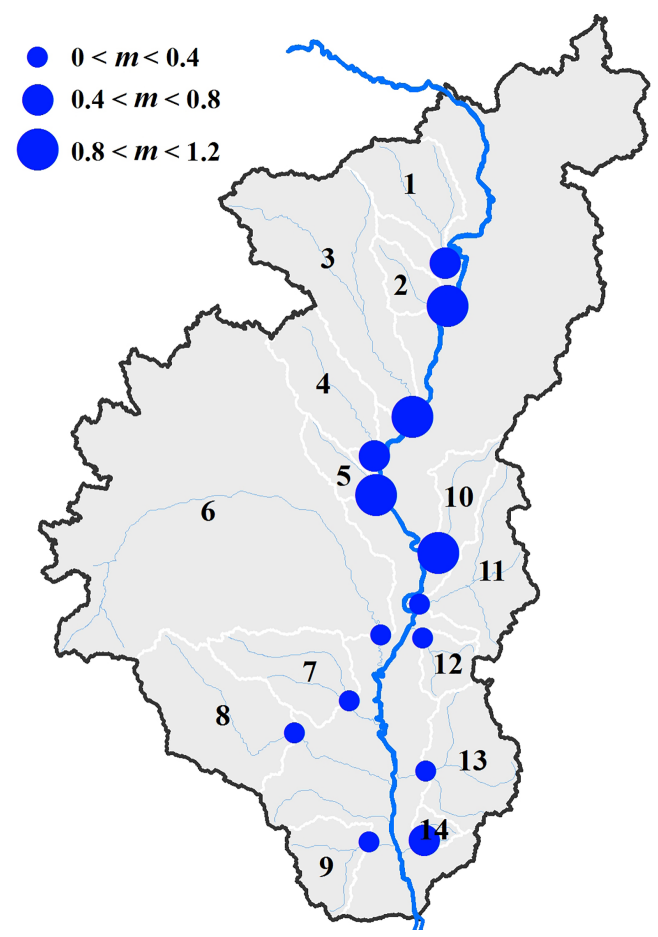

Figure 10. Spatial distribution of slope $m$ in the regression equation $\overline{\mathrm{SC}}=-m A_{\mathrm{c}}+n . \overline{\mathrm{SC}}$ is the decadal average sediment coefficient, and $A_{\mathrm{c}}$ is the percentage of the area affected by soil and water conservation measures in the catchments.

part (Table 5). Based on the slope of the regression equation between the sediment coefficient and fraction of the treated area, the catchments were classified into three groups in Fig. 10 (Group-1: $0.8<m<1.2$; Group-2: $0.4<m<0.8$; and Group-3: $0<m<0.4$ ), which indicated that the degree of sediment load impacted by conservation measures was different among the catchments. The average $m$ value was 0.73 and 0.37 for the catchments in the northwestern and southeastern parts, respectively. Half of the catchments in the northwestern part were in Group-1 and the other half were in Group-2, whereas six of the eight catchments in the southeastern part were in Group-3 with the lowest regression slope.

\subsection{Discussion}

Differences in catchment characteristics, including land use/cover, soil properties, and topography, as well as precipitation characteristics, are clearly the reason for the spatial patterns in the precipitation-sediment yield relationship (Morera et al., 2013; Mutema et al., 2015). The lower vegetation cover was the main reason for the greater effects of precipitation on sediment yield in the northwestern part. In order to fully explore this, the mapping of information of catchment characteristics into sediment yield models and simulations under different climate scenarios would be needed (Ma 

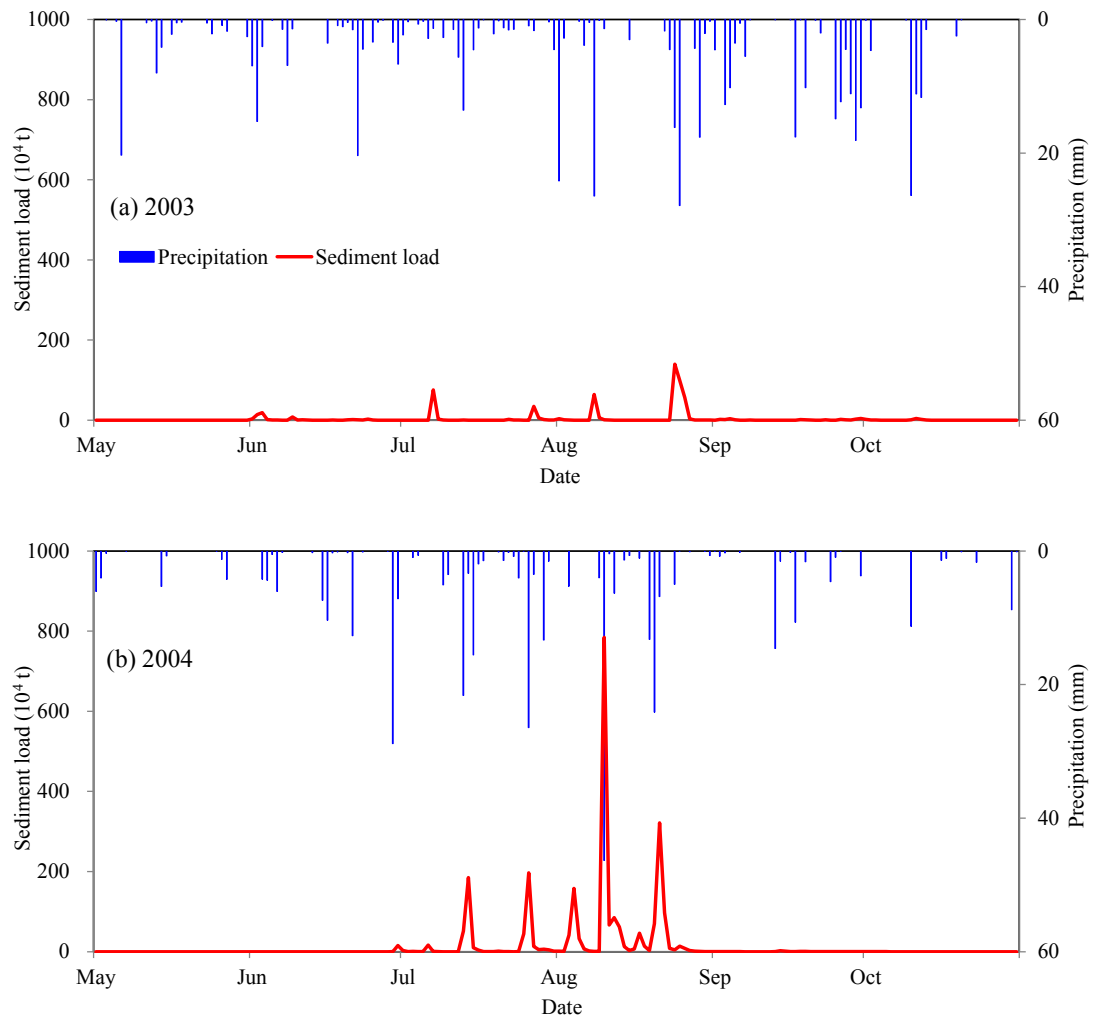

Figure 11. Daily precipitation and sediment load of the Yanhe catchment during the rainy season (May-October) in (a) 2003 and (b) 2004.

Table 6. Pearson correlation coefficients $(r)$ and two-tailed significance test values $(p)$ between sediment yield and annual precipitation $(P)$, number of storms $\left(N_{\text {storm }}\right)$, and precipitation amount of storms $\left(P_{\text {storm }}\right)$ during different decades of the CSHC region.

\begin{tabular}{lrr|rr|rr}
\hline \multirow{2}{*}{ Decades } & \multicolumn{2}{c|}{$P$} & \multicolumn{2}{|c|}{$N_{\text {storm }}$} & \multicolumn{2}{|c}{$P_{\text {storm }}$} \\
\cline { 2 - 7 } & $r$ & $p$ & $r$ & $p$ & $r$ & $p$ \\
\hline $1960 \mathrm{~s}$ & 0.772 & $0.015^{*}$ & 0.808 & $0.008^{* *}$ & 0.718 & $0.029^{*}$ \\
$1970 \mathrm{~s}$ & 0.266 & 0.458 & 0.714 & $0.020^{*}$ & 0.695 & $0.026^{*}$ \\
$1980 \mathrm{~s}$ & 0.775 & $0.009^{* *}$ & 0.633 & $0.050^{*}$ & 0.527 & 0.117 \\
$1990 \mathrm{~s}$ & 0.865 & $0.001^{* * *}$ & 0.591 & 0.072 & 0.572 & 0.084 \\
$2000 \mathrm{~s}$ & 0.118 & 0.715 & 0.006 & 0.986 & 0.138 & 0.669 \\
\hline
\end{tabular}

$* * *, * *$, and $*$ indicate the significance levels of $0.001,0.01$, and 0.05 , respectively.

et al., 2014; Achete et al., 2015). In this context, the interannual and intra-annual patterns of variability of precipitation, including the distribution of storm events, may also contribute to the observed spatial patterns of the precipitationsediment yield relationship.

As LUCC took effect during period-2 and period-3, and despite the much reduced role of precipitation in driving changes in sediment yield, within-year temporal rainfall patterns did play an important role in the observed changes in sediment yield, given that most of the sediment yield was produced during a few key storm events. The correlation between sediment yield and storm events with a daily precipitation amount larger than $20 \mathrm{~mm}$ (including storm numbers, precipitation amount of storms) in the CSHC region during different decades was investigated (see Table 6). The analysis showed that the sediment yield was significantly correlated with storm numbers in the 1960s, 1970s, and 1980s $(p<0.05)$, and precipitation amount of storms in the 1960s and 1970s $(p<0.05)$. This result indicated the critical role of storm events in sediment yield, especially during the periods before substantial LUCC took effect.

Looking into this in more detail and taking the Yanhe catchment as an example, the precipitation amount during the rainy season (May-October when sediment load was measured) in 2003 and 2004 was 514.31 and $389.05 \mathrm{~mm}$, respectively, whereas the sediment load in $2004\left(2427.37 \times 10^{4} \mathrm{t}\right)$ 
was about over 4 times that in $2004\left(590.04 \times 10^{4} \mathrm{t}\right)$. As shown in Fig. 11, there were 6 days with precipitation amounts over $20 \mathrm{~mm}$ and the maximum daily precipitation amount on 25 August was $27.85 \mathrm{~mm}$ in 2003 , and the values in 2004 were 5 days and $46.34 \mathrm{~mm}$ on 10 August. Furthermore, heavy rainfall events were distributed in every month in 2003, whereas they were concentrated in July and August in 2004. There were five evident peaks of sediment load with the sum of $1646.24 \times 10^{4} \mathrm{t}(67.82 \%$ of annual total) in 2004, especially the one on 10 August which produced $784.53 \times 10^{4} \mathrm{t}$ of sediment load $(32.32 \%$ of annual total) (Fig. 11b). In contrast, there were three peaks of sediment load in 2003, and the maximum value was only $139.97 \times 10^{4} \mathrm{t}$ (Fig. 11a). Therefore, apart from annual precipitation amounts, within-year rainfall patterns should also be considered when investigating the effects of precipitation on temporal-spatial changes in streamflow and sediment load.

The sediment load reductions in the CSHC region were primarily caused by the LUCC and the implementation of SWCMs. The cropland area decreased by $9733.91 \mathrm{~km}^{2}$ ( $8.73 \%$ of the region's area) and the forestland area increased by $7662.50 \mathrm{~km}^{2}(6.87 \%$ of the region's area) in the region from 1975 to 2010. Most of the increase in forestland area was converted from cropland area induced by the GFG or reforestation project. As a result of the land use change, vegetation cover increased greatly, and it substantially contributed to the decreases in runoff and sediment production. The SWCMs, such as afforestation and engineering measures, were the major interventions in the study area to reduce the runoff-sediment generation from precipitation and to retain streamflow and sediment load within the catchment. Establishing perennial vegetation cover was considered one of the most effective measures to stabilize soils and minimize erosion (Farley et al., 2005; Liu et al., 2014). It was reported that both the runoff coefficient and sediment concentration of catchments in the LP decreased significantly and linearly with the vegetation cover (Wang et al., 2016). The engineering structures mainly included the creation of terrace and building of check-dams and reservoirs, which reduced flood peaks and stored water and sediment within the catchment. There were about 59874 check-dams in the region which trapped about $9842 \times 10^{4} \mathrm{t}$ of sediment per year (approximately $19 \%$ of annual sediment yield) during the past 6 decades (Yao et al., 2011). Over time, the effectiveness of engineering measures decreased as they progressively filled with sediments, and vegetation restoration played a greater role in controlling soil erosion.

\section{Conclusions}

Through analyses of hydrological and sediment transport data, this study has shown long-term decreasing trends in sediment loads across 15 large sub-catchments located in the CSHC region for the period 1961-2011. The study was particularly aimed at extracting spatio-temporal patterns of sediment yield and attributing these patterns to the broad hydro-climatic and landscape controls. The effects of precipitation variability and land use/cover changes on sediment yield were investigated in detail.

Over the study period, the total area undergoing erosion control treatment went up from only $4 \%$ to over $30 \%$. This included a decrease in cropland by $27 \%$, and an increase in forestland by $53 \%$ and grassland by $4 \%$ from 1975 to 2010. Over the same period annual precipitation decreased by no more than $10 \%$. As a result of the erosion control measures, there were major reductions in streamflow $(65 \%)$, sediment yield (88\%), sediment concentration (68\%), and sediment efficiency, i.e., annual sediment yield/annual precipitation $(86 \%)$ over the entire 50-year period.

The observed data in the 15 study catchments also exhibited interesting spatio-temporal patterns in sediment yield. The study attempted to separate the relative contributions of annual precipitation and LUCC to these spatio-temporal patterns. Before LUCC took effect, the data indicate a linear relationship between the square root of annual sediment yield and annual precipitation in all 15 catchments, with highly variable slopes of the relationship between the catchments, which exhibited systematic spatial patterns, in spite of some scatter. As LUCC increased and took effect, the scatter increased and the slopes of the sediment yield vs. precipitation relationship became highly variable and lost any predictive power. The study then looked at the controls on sediment coefficient instead of sediment yield, thus eliminating the effect of precipitation and enabling a direct focus on landscape controls. The results of this analysis found that the sediment coefficient was heavily dependent on the area under land use/cover treatment, exhibiting a linear decreasing relationship. Even here, there was a considerable variation in the slope of the relationship between the 15 catchments, which exhibited a systematic spatial pattern.

Preliminary analyses presented in this study suggest that much of the sediment yield in the LP may be caused during only a few major storms. Therefore, the seasonality and intra-annual variability of precipitation may play important roles in annual sediment yield, which may also explain the spatial patterns of sediment yield and the effects of the various LUCC. Also, the precipitation threshold for producing sediment yield would have increased greatly as a result of SWCM and vegetation restoration in the LP. Exploration of these questions in detail will require a more physically based model that can account for fine-scale rainfall variability and catchment characteristics. This is the next immediate step in our investigations, and will be reported on in the near future.

Data availability. All the data used in this study are available upon request. 
Competing interests. The authors declare that they have no conflict of interest.

Acknowledgements. This research was funded by the National Key Research and Development Program of China (no. 2016YFC0501602), the National Natural Science Foundation of China (no. 41471094), the Chinese Academy of Sciences (no. GJHZ 1502), and the Youth Innovation Promotion Association CAS (no. 2016040). We thank the Ecological Environment Database of Loess Plateau, the Yellow River Conservancy Commission, and the National Meteorological Information Center for providing the hydrological and meteorological data. We thank the three anonymous reviewers for their valuable and detailed comments which greatly improved the quality of this paper.

Edited by: Nunzio Romano

Reviewed by: three anonymous referees

\section{References}

Achete, F. M., van der Wegen, M., Roelvink, D., and Jaffe, B.: A 2D process-based model for suspended sediment dynamics: a first step towards ecological modeling, Hydrol. Earth Syst. Sci., 19, 2837-2857, https://doi.org/10.5194/hess-19-2837-2015, 2015.

Beechie, T. J., Sear, D. A., Olden, J. D., Pess, G. R., Buffington, J. M., Moir, H., Roni, P., and Pollock, M. M.: Process-based principles for restoring river ecosystems, Bioscience, 60, 209-222, 2010.

Chen, Y. P., Wang, K. B., Lin, Y. S., Shi, W. Y., Song, Y., and He, X. H.: Balancing green and grain trade, Nat. Geosci., 8, 739-741, 2015.

Cohen, S., Kettner, A. J., and Syvitski, J. P. M.: Global suspended sediment and water discharge dynamics between 1960 and 2010: continental trends and intra-basin sensitivity, Glob. Planet. Change, 115, 44-58, 2014.

Farley, K. A., Jobbágy, E. G., and Jackson, R. B.: Effects of afforestation on water yield: a global synthesis with implications for policy, Glob. Change Biol., 11, 1565-1576, 2005.

Gao, G. Y., Fu, B. J., Wang, S., Liang, W., and Jiang, X. H.: Determining the hydrological responses to climate variability and land use/cover change in the Loess Plateau with the Budyko framework, Sci. Total Environ., 557/558, 331-342, 2016.

Hirsch, R. M., Slack, J. R., and Smith, R. A.: Techniques of trend analysis for monthly water quality data, Water Resour. Res., 18, 107-121, 1982.

Kendall, M. G.: Rank Correlation Measures, Charles Griffin, London, UK, 1975.

Liu, X. Y., Yang, S. T., Dang, S. Z., Luo, Y., Li, X. Y., and Zhou, $\mathrm{X}$ : Response of sediment yield to vegetation restoration at a large spatial scale in the Loess Plateau, Sci. China Tech. Sci., 57, 1482-1489, 2014.

Ma, X., Lu, X. X., van Noordwijk, M., Li, J. T., and Xu, J. C.: Attribution of climate change, vegetation restoration, and engineering measures to the reduction of suspended sediment in the Kejie catchment, southwest China, Hydrol. Earth Syst. Sci., 18, 1979-1994, https://doi.org/10.5194/hess-18-1979-2014, 2014.
Mann, H. B.: Nonparametric tests against trend, Econometrica, 13, 245-259, 1945.

McVicar, T. R., Li, L. T., Van Niel, T. G., Zhang, L., Li, R., Yang, Q. K., Zhang, X. P., Mu, X. M., Wen, Z. M., Liu, W. Z., Zhao, Y. A., Liu, Z. H., and Gao, P.: Developing a decision support tool for China's re-vegetation program: simulating regional impacts of afforestation on average annual streamflow in the Loess Plateau, For. Ecol. Manag., 251, 65-81, 2007.

Miao, C. Y., Ni, J. R., and Borthwick, A. G. L.: Recent changes of water discharge and sediment load in the Yellow River basin, China, Prog. Phys. Geogr., 34, 541-561, 2010.

Miao, C. Y., Ni, J. R., Borthwick, A. G. L., and Yang, L.: A preliminary estimate of human and natural contributions to the changes in water discharge and sediment load in the Yellow River, Glob. Planet. Change, 76, 196-205, 2011.

Milliman, J. D., Farnsworth, K. L., Jones, P. D., Xu, K. H., and Smith, L. C.: Climatic and anthropogenic factors affecting river discharge to the global ocean, 1951-2000, Glob. Planet. Change, 62, 187-194, 2008.

Milly, P. C. D., Dunne, K. A., and Vecchia, A. V.: Global pattern of trends in streamflow and water availability in a changing climate, Nature, 438, 347-350, 2005.

Morera, S. B., Condom, T., Vauchel, P., Guyot, J.-L., Galvez, C., and Crave, A.: Pertinent spatio-temporal scale of observation to understand suspended sediment yield control factors in the Andean region: the case of the Santa River (Peru), Hydrol. Earth Syst. Sci., 17, 4641-4657, https://doi.org/10.5194/hess-17-46412013, 2013.

Mutema, M., Chaplot, V., Jewitt, G., Chivenge, P., and Blöschl, G.: Annual water, sediment, nutrient, and organic carbon fluxes in river basins: A global meta-analysis as a function of scale, Water Resour. Res., 51, 8949-8972, https://doi.org/10.1002/2014WR016668, 2015.

Nilsson, C., Reidy, C. A., Dynesius, M., and Revenga, C.: Fragmentation and flow regulation of the world's large river systems, Science, 308, 405-408, 2005.

Rustomji, P., Zhang, X. P., Hairsine, P. B., Zhang, L., and Zhao, J.: River sediment load and concentration responses to changes in hydrology and catchment management in the Loess Plateau of China, Water Resour. Res., 44, W00A04, https://doi.org/10.1029/2007WR006656, 2008.

Sen, P. K.: Estimates of the regression coefficient based on Kendall's tau, J. Am. Stat. Assoc., 63, 1379-1389, 1968.

Song, C. L., Wang, G. X., Sun, X. Y., Chang, R. Y., and Mao, T. X.: Control factors and scale analysis of annual river water, sediments and carbon transport in China, Sci. Rep., 6, 25963, https://doi.org/10.1038/srep25963, 2016.

Sun, Q. H., Miao, C. Y., Duan, Q. Y., and Wang, Y. F.: Temperature and precipitation changes over the Loess Plateau between 1961 and 2011, based on high-density gauge observations, Glob. Planet. Change, 132, 1-10, 2015a.

Sun, W. Y., Song, X. Y., Mu, X. M., Gao, P., Wang, F., and Zhao, G. J.: Spatiotemporal vegetation cover variations associated with climate change and ecological restoration in the Loess Plateau, Agr. Forest Meteorol., 209, 87-99, 2015b.

Syvitski, J. P. M.: Supply and flux of sediment along hydrological pathways: Research for the 21st century, Glob. Planet. Change, 39, 1-11, 2003. 
Syvitski, J. P. M., Vörösmarty, C. J., Kettner, A. J., and Green, P.: Impact of humans on the flux of terrestrial sediment to the global coastal ocean, Science, 308, 376-380, 2005.

Walling, D. E.: Human impact on land-ocean sediment transfer by the world's rivers, Geomorphology, 79, 192-216, 2006.

Walling, D. E. and Fang, D.: Recent trends in the suspended sediment loads of the world rivers, Glob. Planet. Change, 39, 111126, 2003.

Wang, H. J., Saito, Y., Zhang, Y., Bi, N. S., Sun, X. X., and Yang, Z. S.: Recent changes of sediment flux to the western Pacific Ocean from major rivers in east and south-east Asia, Earth Sci. Rev., 108, 80-100, 2011.

Wang, S., Fu, B., Piao, S., Lü, Y., Philippe, C., Feng, X., and Wang, Y.: Reduced sediment transport in the Yellow River due to anthropogenic changes, Nat. Geosci., 9, 38-41, 2016.

Yao, W. Y., Xu, J. H., and Ran, D. C.: Assessment of Changing Trends in Streamflow and Sediment Fluxes in the Yellow River Basin, Yellow River Water Conservancy Press, Zhengzhou, China, 2011 (in Chinese).

Yue, S. and Wang, C. Y.: Applicability of pre-whitening to eliminate the influence of serial correlation on the Mann-Kendall test, Water Resour. Res., 38, 1068, https://doi.org/10.1029/2001WR000861, 2002.
Zhang, B. Q., He, C. S., Burnham, M., and Zhang, L. H.: Evaluating the coupling effects of climate aridity and vegetation restoration on soil erosion over the Loess Plateau in China, Sci. Total Environ., 539, 436-449, 2016.

Zhang, L., Zhao, F. F., Chen, Y., and Dixon, R. N. M.: Estimating effects of plantation expansion and climate variability on streamflow for catchments in Australia, Water Resour. Res., 47, W12539, https://doi.org/10.1029/2011WR010711, 2011.

Zhao, G. J., Mu, X. M., Jiao, J. Y., An, Z. F., Klik, A., Wang, F., Jiao, F., Yue, X. L., Gao, P., and Sun, W. Y.: Evidence and causes of spatiotemporal changes in runoff and sediment yield on the Chinese Loess Plateau, Land Degrad. Dev., 28, 579-590, 2017.

Zhao, X., Liang, S. L., Liu, S. H., Yuan, W. P., Xiao, Z. Q., Liu, Q., Cheng, J., Zhang, X. T., Tang, H. R., Zhang, X., Liu, Q., Zhou, G. Q., Xu, S., and Yu, K.: The global land surface satellite (GLASS) remote sensing data processing system and products, Remote Sens., 5, 2436-2450, 2013. 